\title{
CD44 variant 9 expression as a predictor for gastric cancer recurrence: immunohistochemical and metabolomic analysis of surgically resected tissues
}

\author{
Yushi Yamakawa ${ }^{1,2}$, Masatoshi Kusuhara ${ }^{3}$, Masanori Terashima ${ }^{4}$, Yusuke Kinugasa ${ }^{1}$, Takashi Sugino ${ }^{5}$, Masato \\ $\mathrm{AbE}^{5}$, Toru Mochizuki ${ }^{6}$, Keiichi Hatakeyama ${ }^{6}$, Kenjiro $\mathrm{Kami}^{7}$, and Ken Yamaguchi ${ }^{8}$ \\ ${ }^{1}$ Division of Colon and Rectal Surgery, Shizuoka Cancer Center, Shizuoka, Japan; ${ }^{2}$ Department of Surgery, School of Medicine, Keio \\ University, Tokyo, Japan; ${ }^{3}$ Regional Resources Division, Shizuoka Cancer Center Research Institute, Shizuoka, Japan; ${ }^{4}$ Division of \\ Gastric Surgery, Shizuoka Cancer Center, Shizuoka, Japan; ${ }^{5}$ Division of Pathology, Shizuoka Cancer Center, Shizuoka, Japan; ${ }^{6}$ Medical \\ Genetics Division, Shizuoka Cancer Center Research Institute, Shizuoka, Japan; ${ }^{7}$ Human Metabolome Technologies, Inc., Tsuruoka, \\ Yamagata, Japan; and ${ }^{8}$ Shizuoka Cancer Center, Shizuoka, Japan
}

(Received 29 October 2016; and accepted 11 November 2016)

\begin{abstract}
CD44 variant 9 (CD44v9) and the heavy chain of 4F2 cell-surface antigen (CD98hc) appear important for regulation of reactive oxygen species defence and tumor growth in gastric cancer. This study examined the roles of CD44v9 and CD98hc as markers of gastric cancer recurrence, and investigated associations with energy metabolism. We applied capillary electrophoresis time-of-flight mass spectrometry to metabolome profiling of gastric cancer specimens from 103 patients who underwent resection with no residual tumor or microscopic residual tumor, and compared metabolite levels to immunohistochemical staining for CD44v9 and CD98hc. Positive expression rates were $40.7 \%$ for CD44v9 and $42.7 \%$ for CD98hc. Various tumor characteristics were significantly associated with CD44v9 expression. Five-year recurrence-free survival rate was significantly lower for CD44v9-positive tumors $(39.1 \%)$ than for CD44v9-negative tumors $(73.5 \% ; P<0.0001)$, but no significant differences in recurrence-free survival were seen according to CD98hc expression. Uniand multivariate analyses identified positive CD44v9 expression as an independent predictor of poorer recurrence-free survival. Metabolome analysis of 110 metabolites found that levels of glutathione disulfide were significantly lower and reduced glutathione (GSH)/ glutathione disulfide (GSSG) ratio was significantly higher in CD44v9-positive tumors than in CD44v9-negative tumors, suggesting that $\mathrm{CD} 44 \mathrm{v} 9$ may enhance pentose phosphate pathway flux and maintain GSH levels in cancer cells.
\end{abstract}

Gastric cancer is the fifth most common malignancy $(952,000$ cases in 2012) and the third leading cause of cancer-related deaths $(723,000$ deaths in 2012) worldwide (1). Despite the decline in global patient numbers, gastric cancer remains one of the most

Address correspondence to: Masatoshi Kusuhara, MD, $\mathrm{PhD}$.

Regional Resources Division, Shizuoka Cancer Center Research Institute, 1007 Shimonagakubo, Nakatogaricho, Sunto-gun, Shizuoka 411-8777, Japan

Tel: +81-55-989-5222, Fax: +81-55-989-5783

E-mail: m.kusuhara@scchr.jp prevalent cancers in Japan. Although progress in early diagnosis and adjuvant therapy has improved outcomes for gastric cancer patients, radical surgery remains the primary approach for gastric cancer treatment. Outcomes are still unsatisfactory, because gastric cancers relapse with local or distant metastasis even after radical gastrectomy. More specific diagnostic and therapeutic targets are urgently needed to achieve better clinical applications in this field.

CD44, a major adhesion molecule for the extracellular matrix, is a single-pass type I transmembrane protein that serves as a cell surface receptor for hyaluronic acid, and has been implicated in vari- 
ous biological processes, such as cell adhesion, cell migration, and cancer metastasis $(3,12,18,38,45)$. This molecule exists in numerous isoforms containing at least 20 exons in different combinations generated through alternative mRNA splicing (47). However, the functional relevance of CD44 variants in tumor cells remains unclear. Splice variants play important roles within the cell in both increasing proteome diversity and in cellular function. Splice variants are also associated with disease states and may play etiological roles (16).

CD44 has recently been identified as one of the cell surface markers associated with cancer stem cells in several types of tumor $(2,11)$. Among CD44 variants, CD44 variant 9 (CD44v9) is highly expressed by cancer stem cells in mouse gastric cancers (26). Cancer stem cells that exhibit stem celllike characteristics such as multilineage potential and self-renewal potential have been identified in cancer tissues (41). Cancer stem cells are resistant to therapy because they show enhanced protection against reactive oxygen species (ROS) (13). In addition, CD44v9 may contribute to cancer survival under hostile conditions, such as with the condition of high ROS generation from chemoradiotherapy, by increasing intracellular levels of reduced glutathione (GSH) through an activating xCT, a glutamate-cystine exchange transporter (25). Such findings suggest that CD44v9-positive cells have a specific function in protecting against ROS, and contribute to features of cancer stem cells. In addition, expression of CD44v9 in tumor tissues has also been associated with tumor recurrence and prognosis in patients with several types of cancer $(4,19,20,31,33)$.

Recently, expression levels of CD44v9 in early gastric cancer have also been shown to correlate positively with the risk of recurrence in patients who underwent endoscopic submucosal dissection (21). Furthermore, expression levels of CD44v9 in head and neck cancer cell lines were associated with increased levels of intracellular GSH and resistance to cisplatin (52). Sulfasalazine, a drug used in the treatment of inflammatory bowel disease, is a specific inhibitor of xCT-mediated cystine transporters and was recently shown to selectively damage CD44v9 expressing cells, suppress CD44v9-dependent tumor growth, and enhance sensitivity to cisplatin $(25,46)$. These findings suggest that CD44v9 might represent a good target for cancer treatment. However, whether CD44v9-positive cells demonstrate aspects of cancer stem cells and whether CD44v9 can be a biomarker for gastric cancer recurrence remain elusive.

On the other hand, xCT and L-type amino-acid transporter 1 (LAT1) transport large neutral amino acids, and require covalent association with the heavy chain of 4F2 cell-surface antigen (CD98hc) for functional expression in the plasma membrane $(32,48)$. CD98hc has a main biochemical function of amino acid transport, and appears important in tumor growth and metastasis (9). LAT1, the most well-studied CD98 light chain, is classified as an bi-directional transporter of large neutral amino acids. Recent studies have shown that high LAT1 expression is significantly associated with poor outcomes for various human cancers, such as gastric cancer, colorectal cancer, lung cancer, prostate cancer, breast cancer, and renal cell carcinoma $(5,17,24,28,49,50)$. However, no studies have clarified the relationship between CD98hc expression and gastric cancer recurrence. Metabolome analysis has recently been applied to the characterization of cancer-cell-specific metabolism. Levels of most amino acids and their primary derivatives have been found to be significantly higher in tumors than in normal tissue by quantitative metabolome profiling (22).

The development of metabolome analysis tools is allowing the application of comprehensive analyses of energy metabolism pathways such as glycolysis, pentose phosphate pathway (PPP), tricarboxylic acid (TCA) cycle, urea cycle, amino acid and nucleotide metabolisms, and GSH metabolism in cells and tissues. Several articles have been published on metabolomic applications in gastric cancer $(27,34,35)$. However, none have focused on associations between energy metabolism and CD44v9 expression. The first aim of this study was thus to determine the role of CD44v9 and CD98hc as a marker of gastric cancer recurrence. The second was to identify associations of energy metabolism, especially GSH metabolism, with CD44v9 and CD98hc; to this end, we applied capillary electrophoresis time-of-flight mass spectrometry (CE-TOFMS) to the metabolome profiling of human gastric cancer, and compared metabolite levels to CD44v9 and CD98hc expression in tumor tissues obtained by surgery.

\section{MATERIALS AND METHODS}

Patients. Participants in this study comprised 103 patients with gastric cancer who underwent resection with no residual tumor or microscopic residual tumor between February 2011 and May 2012 at Shizuoka Cancer Center. In general, patients received adjuvant chemotherapy with tegafur/gimeracil/oteracil known as S-1 for 1 year if the pathological stage was II or III. In addition, some stage IV patients also received 
chemotherapy with S-1 for 1 or 2 years, as decided by the physician. Patients were routinely followed-up every 3 to 6 months for up to 5 years. Median duration of follow-up was 61.0 months. Recurrence was diagnosed by image findings using computed tomography (CT), ultrasonography and magnetic resonance imaging (MRI). This study was approved by the Human Ethics Review Committee of Shizuoka Cancer Center, and written informed consent was obtained from each patient prior to enrolment.

Tissue samples. For metabolite extraction, tumor and surrounding non-tumor tissues were collected from surgically resected samples immediately after gastrectomy. The resected tissue samples were immediately frozen in liquid nitrogen and stored at $-80^{\circ} \mathrm{C}$ until metabolite extraction. The rest of all surgical specimens were fixed in $10 \%$ formalin neutral buffer solution and embedded in paraffin. All slides were reviewed by more than two pathologists and histologically confirmed to be gastric carcinoma. Tumors were staged according to the 14th Japanese Gastric Cancer Association staging system.

Histology and immunohistochemistry. We performed immunohistochemical staining for CD44v9 and CD98hc. Tissue was fixed in neutral-buffered $10 \%$ formalin solution, embedded in paraffin, and sectioned at a thickness of $4 \mu \mathrm{m}$. Sections were depleted of paraffin, then rehydrated in a graded series of ethanol solutions. For histology, sections were stained with hematoxylin and eosin.

Staining for CD44v9 was carried out using the avidin-biotin complex peroxidase method. For immunohistochemistry, following deparaffinization and rehydration, antigen for anti-CD44v9 (RV3; $1: 5000$ dilution; Cosmo Bio, Tokyo, Japan) was retrieved by heating samples in buffered Tris-EDTA ( $\mathrm{pH}$ 9.0) for $40 \mathrm{~min}$ at $98^{\circ} \mathrm{C}$. The sections were then incubated with the rat antibody for overnight at room temperature. After washing with phosphate-buffered solution, they were incubated with secondary antibody (BA-4000, biotinylated rabbit anti-rat IgG antibody; Vector Laboratories, Burlingame, CA) for $30 \mathrm{~min}$. Immune complexes were detected using a Liquid DAB + Substrate Chromogen System (K3468; Dako, Carpinteria, CA), and the sections were counterstained with hematoxylin.

Staining for CD98hc was carried out using the high-molecular polymer method. The Bond Polymer Refine Detection Kit (DS9800; Vision BioSystems, Melbourne, Australia) was applied using anti-CD98hc (sc-9160, 1: 100 dilution; Santa Cruz Biotechnolo- gy, Santa Cruz, CA) antibodies for $15 \mathrm{~min}$ at room temperature. The procedure was performed using the autostainer Bond-III processing module (\#21005; Vision BioSystems) according to the instructions from the manufacturer. Finally, sections were washed in water and counterstained with hematoxylin.

CD44v9 and CD98hc immunoreactive scores were defined independently according to the intensity of cellular staining and the proportion of stained tumor cells. Staining intensity was scored as: 0 , no staining; 1, weak staining; 2, moderate staining; and 3 , strong staining. Proportions of stained tumor cells were classified as: $0, \leq 5 \%$ positive cells; $1,6-25 \%$ positive cells; $2,26-50 \%$ positive cells; and $3, \geq 51 \%$ positive cells. Total scores for intensity and proportion were used to signify levels of protein expression. A score of $\leq 3$ was considered to represent negative expression, and a score of $\geq 4$ was considered positive expression. Two authors blinded to patient data independently evaluated immunoreactivity for CD44v9 and CD98hc.

Metabolite extraction. Approximately $50 \mathrm{mg}$ of frozen tissue was plunged into $1,500 \mu \mathrm{L}$ of $50 \%$ acetonitrile/Milli-Q water containing internal standards (H3304-1002; Human Metabolome Technologies, Tsuruoka, Japan) at $0^{\circ} \mathrm{C}$ in order to inactivate enzymes. Tissue was homogenized three times at 1,500 $\mathrm{rpm}$ for $120 \mathrm{~s}$ using a tissue homogenizer (Microsmash MS100R; Tomy Digital Biology, Tokyo, Japan), then the homogenate was centrifuged at $2,300 \times g$ and $4^{\circ} \mathrm{C}$ for $5 \mathrm{~min}$. Subsequently, $800 \mu \mathrm{L}$ of the upper aqueous layer was centrifugally filtered through a Millipore 5,000-Da cutoff filter at 9,100 $\times g$ and $4^{\circ} \mathrm{C}$ for $120 \mathrm{~min}$ to remove proteins. The filtrate was centrifugally concentrated and re-suspended in $50 \mu \mathrm{L}$ of Milli-Q water for CE-TOFMS analysis.

Metabolome analysis. Metabolome analysis was conducted using the Basic Scan package of HMT using CE-TOFMS based on previously described methods $(39,40)$. Briefly, CE-TOFMS analysis was carried out using an Agilent CE capillary electrophoresis system equipped with an Agilent 6210 time-of-flight mass spectrometer (Agilent Technologies, Waldbronn, Germany). Systems were controlled using Agilent G2201AA ChemStation for CE version B.03.01 software (Agilent Technologies). The spectrometer was scanned from $\mathrm{m} / \mathrm{z} 50$ to 1,000 and peaks were extracted using MasterHands automatic integration software (Keio University, Tsuruoka, Yamagata, Japan) to obtain peak information including $\mathrm{m} / \mathrm{z}$, peak area, and migration time (43). Signal peaks corre- 
Table 1 Patients' characteristics

\begin{tabular}{|c|c|c|c|c|c|}
\hline Clinicopathological Parameters & $\begin{array}{l}\text { Patients } \\
(n=103)\end{array}$ & $\%$ & Clinicopathological Parameters & $\begin{array}{l}\text { Patients } \\
(n=103)\end{array}$ & $\%$ \\
\hline Gender & & & Venous invasion & & \\
\hline Male & 79 & 76.7 & Absent & 26 & 25.2 \\
\hline Female & 24 & 23.3 & Present & 77 & 74.8 \\
\hline Age (years) & & & Pathological T stage & & \\
\hline$<70$ & 52 & 50.5 & $\mathrm{~T} 1$ & 10 & 9.7 \\
\hline$\geq 70$ & 51 & 49.5 & $\mathrm{~T} 2$ & 9 & 8.7 \\
\hline CEA (ng/mL) & & & $\mathrm{T} 3$ & 27 & 26.3 \\
\hline$<5.0$ & 84 & 81.6 & $\mathrm{~T} 4$ & 57 & 55.3 \\
\hline$\geq 5.0$ & 19 & 18.4 & Pathological N stage & & \\
\hline Location & & & No & 29 & 28.2 \\
\hline Upper & 32 & 31.1 & N1 & 16 & 15.5 \\
\hline Middle & 22 & 21.3 & N2 & 14 & 13.6 \\
\hline Lower & 49 & 47.6 & N3 & 44 & 42.7 \\
\hline Tumor size (mm) & & & Pathological TNM stage & & \\
\hline$<70$ & 54 & 52.4 & I & 13 & 12.6 \\
\hline$\geq 70$ & 49 & 47.6 & II & 24 & 23.3 \\
\hline Histologic type & & & III & 43 & 41.8 \\
\hline Differentiated & 49 & 47.6 & IV & 23 & 22.3 \\
\hline Undifferentiated & 54 & 52.4 & Residual tumor & & \\
\hline Lymphatic invasion & & & no & 83 & 80.6 \\
\hline Absent & 27 & 26.2 & microscopic & 20 & 19.4 \\
\hline Present & 76 & 73.8 & & & \\
\hline
\end{tabular}

sponding to isotopomers, adduct ions, and other product ions of known metabolites were excluded, and the remaining peaks were annotated according to the HMT metabolite database based on $\mathrm{m} / \mathrm{z}$ values with the migration times. Areas of the annotated peaks were normalized based on internal standard levels and sample amounts to obtain relative levels of each metabolite.

Statistical analysis. All statistical analyses were carried out using $\mathrm{JMP}^{\circledR}$ version 12 software (SAS Institute, Cary, NC). The statistical significance of any associations between CD44v9 and CD98hc immunohistochemical staining and various clinicopathological variables was evaluated using the $\chi^{2}$ and Fisher's tests. Survival curves were calculated from the day of surgery to relapse, death, or last follow-up observation using the Kaplan-Meier method, and differences in recurrence-free survival (RFS) curves were assessed with the log-rank test. To assess prognostic markers of disease recurrence, we first performed univariate analysis. Significant parameters from univariate analysis were then assessed in the final multivariate analysis using Cox proportional hazards regression modeling with step-wise forward selection.

\section{RESULTS}

\section{Patient characteristics}

Patient characteristics are shown in Table 1. Since participants comprised those whose tumors were large enough to allow tumor tissue collection for metabolite extraction, most patients $(90.3 \%)$ showed advanced cancer. All patients who underwent resection with microscopic residual tumor showed positive peritoneal cytology. Patients who underwent resection with microscopic residual tumor included one patient with hepatic metastases and one patient with minimal peritoneal metastases that were completely resected simultaneously. Postoperative adjuvant tegafur/gimeracil/oteracil known as S-1 chemotherapy performed for stage II/III was administered to $61.2 \%$ of patients (41 patients).

Expression of CD44v9 and CD98he in gastric cancer tumor tissue

All tissue slides were re-reviewed by two pathologists. Positive expression rates were $40.7 \%$ for CD44v9 (CD44v9-positive) and 42.7\% for CD98hc (CD98hc-positive) (Supplementary Fig. 1). Representative images of immunohistochemical staining for CD44v9 and CD98he are shown in Supplementary Fig. 2. 
Table 2 Relationships between CD44v9 and CD98hc expression statuses and clinicopathological characteristics

\begin{tabular}{|c|c|c|c|c|c|}
\hline \multicolumn{2}{|c|}{ Clinicopathological Characteristics } & \multirow{2}{*}{$\begin{array}{c}\text { Positive CD44v9 } \\
(n=42)(\%)\end{array}$} & \multirow{2}{*}{$\begin{array}{l}P \text { value } \\
0.708\end{array}$} & \multirow{2}{*}{$\begin{array}{c}\begin{array}{c}\text { Positive CD98hc } \\
(n=44)(\%)\end{array} \\
34(43.0)\end{array}$} & \multirow{2}{*}{$\begin{array}{r}P \text { value } \\
0.905\end{array}$} \\
\hline Gender & Male & & & & \\
\hline & Female & $9(37.5)$ & & $10(41.7)$ & \\
\hline \multirow[t]{2}{*}{ Age (years) } & $<70$ & $21(40.4)$ & 0.935 & $20(38.5)$ & 0.377 \\
\hline & $\geq 70$ & $10(41.2)$ & & $17(47.1)$ & \\
\hline \multirow[t]{2}{*}{ CEA (ng/mL) } & $<5.0$ & $34(40.5)$ & 0.896 & $37(44.5)$ & 0.566 \\
\hline & $\geq 5.0$ & $8(42.1)$ & & $7(36.8)$ & \\
\hline \multirow[t]{3}{*}{ Location } & Upper & $11(34.4)$ & 0.473 & $13(40.6)$ & 0.913 \\
\hline & Middle & $8(36.4)$ & & $9(40.9)$ & \\
\hline & Lower & $23(46.9)$ & & $22(44.9)$ & \\
\hline \multirow[t]{2}{*}{ Tumor size (mm) } & $<70$ & $16(29.6)$ & 0.013 & $22(40.7)$ & 0.672 \\
\hline & $\geq 70$ & $26(53.1)$ & & $22(44.9)$ & \\
\hline \multirow[t]{2}{*}{ Histologic type } & Differentiated & $16(32.6)$ & 0.11 & $21(38.9)$ & 0.409 \\
\hline & Undifferentiated & $26(48.2)$ & & $23(46.9)$ & \\
\hline \multirow[t]{2}{*}{ Lymphatic invasion } & Absent & $10(37.0)$ & 0.644 & $13(48.2)$ & 0.507 \\
\hline & Present & $32(42.1)$ & & $31(40.8)$ & \\
\hline \multirow[t]{2}{*}{ Venous invasion } & Absent & $9(34.6)$ & 0.457 & $10(38.5)$ & 0.612 \\
\hline & Present & $33(42.9)$ & & $34(44.2)$ & \\
\hline \multirow[t]{2}{*}{ Pathological T stage } & $\mathrm{T} 1-2$ & $1(5.26)$ & 0.0001 & $11(57.9)$ & 0.141 \\
\hline & T3-4 & $41(48.8)$ & & $33(36.3)$ & \\
\hline \multirow[t]{4}{*}{ Pathological N stage } & No & $7(24.1)$ & 0.0075 & $11(37.93)$ & 0.807 \\
\hline & N1 & $6(37.5)$ & & $8(50.0)$ & \\
\hline & $\mathrm{N} 2$ & $3(21.4)$ & & $7(50.0)$ & \\
\hline & $\mathrm{N} 3$ & $26(59.1)$ & & $18(40.9)$ & \\
\hline \multirow[t]{4}{*}{ Pathological TNM stage } & I & $0(0.0)$ & 0.0003 & $6(46.2)$ & 0.311 \\
\hline & II & $8(33.3)$ & & $12(50.0)$ & \\
\hline & III & $20(46.5)$ & & $20(46.5)$ & \\
\hline & IV & $14(60.9)$ & & $6(26.1)$ & \\
\hline \multirow[t]{2}{*}{ Residual tumor } & no & $28(33.7)$ & 0.0031 & $39(47.0)$ & 0.074 \\
\hline & microscopic & $14(70.0)$ & & $5(25.0)$ & \\
\hline
\end{tabular}

Clinically relevant background factors in the CD44v9-positive and CD98hc-positive groups are shown in Table 2. Tumor size, pathological $\mathrm{T}$ stage, pathological N stage, pathological TNM stage, and residual tumor were all found to be significantly related to $\mathrm{CD} 44 \mathrm{v} 9$ expression. On the other hand, no significant differences in any characteristics were observed between CD98hc-positive and -negative groups. During the median follow-up of 61.0 months, tumor recurrence (including local and distant metastasis) was observed in 37 patients $(35.9 \%)$. The most frequent recurrence pattern was peritoneal metastasis, which was observed in 24 patients $(64.9 \%)$, followed by distant lymphatic metastasis in 14 patients (37.8\%). Hepatic metastasis was observed in six patients $(16.2 \%)$. Pulmonary metastasis was observed in one patient $(2.7 \%)$. Multiple metastases were observed in seven $(18.9 \%)$ of the 37 patients at initial recurrence.

During the study period, 35 patients $(34.0 \%)$ died. Of these, $31(88.6 \%)$ died of recurrent gastric cancer and four (11.4\%) died of another disease without recurrence. No patients died of other malignancies.

\section{Prognostic role of CD44v9 and CD98he in gastric} cancer patients

In this study, disease recurrence was identified in 26 patients $(26 / 42,61.9 \%)$ in the CD44v9-positive group and 9 patients $(9 / 61,14.8 \%)$ in the CD44v9-negative group. Fig. 1 shows the Kaplan-Meier curves for recurrence-free survival (RFS) in these two groups of gastric cancer patients. Five-year RFS rates were $39.1 \%$ for CD44v9-positive tumors and $73.5 \%$ for CD44v9-negative tumors, representing a significant difference between groups $(P<0.0001)$. Fiveyear RFS rate according to CD98hc expression was $60.7 \%$ for CD 98 hc-positive and $58.7 \%$ for CD98hcnegative. No significant difference was observed between the CD98hc-positive and -negative groups $(P=0.690)$ (Fig. 2). When we analyzed patients with gastric cancers of pathologic stages I through IV separately, CD44v9-positive patients showed worse 


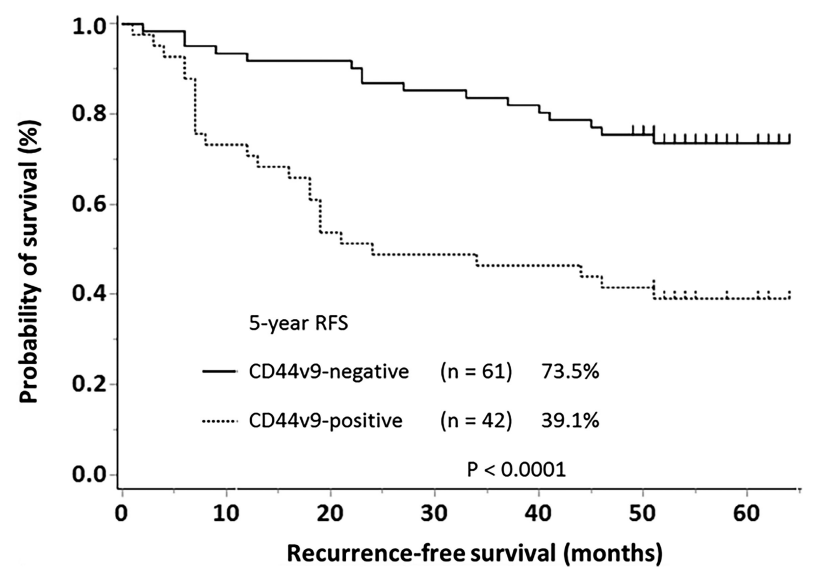

Fig. 1 Kaplan-Meier curve for recurrence-free survival according to CD44v9 status in all patients. Five-year RFS rate was significantly lower for patients in the CD44v9-positive group than for patients in the CD44v9-negative group (39.1 vs. $73.5 \%$; $P<0.0001$ )

RFS than CD44v9-negative patients in stage III $(P=0.0082)$ (Supplementary Fig. 3). At stage III, 5 -year RFS rates were $35.3 \%$ for CD44v9-positive and $76.5 \%$ for CD44v9-negative tumors. However, no significant differences in survival were seen at any stage according to CD98hc expression (data not shown).

Univariate Cox regression analysis revealed that tumor size $\geq 70 \mathrm{~mm}(P=0.010)$, undifferentiated histological type $(P=0.009)$, pathological stage T3/4 $(P=0.0007)$, positive lymph node metastasis $(P<$ $0.0001)$, and positive CD44v9 expression $(P<0.0001)$ correlated with worse RFS. Multivariate analysis identified undifferentiated histological type $[P=0.034$, hazard ratio $=2.11(1.054-4.547)]$, positive lymph node metastasis $[P=0.0005$, hazard ratio $=6.92$ (2.074-43.00)], and positive CD44v9 expression $[P<0.0001$, hazard ratio $=4.14(1.997-9.286)]$ as independent prognostic factors for RFS (Table 3).

\section{Metabolome analyses of gastric cancer tissues}

We analyzed metabolome profiles of tumor tissues obtained from the 103 gastric cancer patients using CE-TOFMS. Based on $\mathrm{m} / \mathrm{z}$ values and migration time, 110 metabolites were measured in gastric tissues. Most GSH metabolism intermediates were quantified (Fig. 3). Levels of GSH, cysteine, and glutamate did not differ statistically between CD44v9positive and -negative groups, although levels of glutathione disulfide (GSSG) and GSH/GSSG ratio were significantly lower and higher, respectively, in gastric cancer tissue from the CD44v9-positive group than from the CD44v9-negative group.

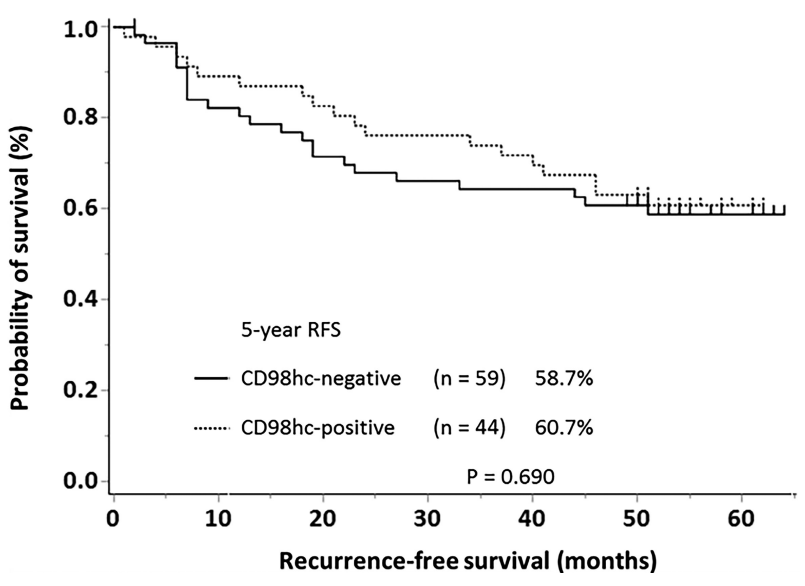

Fig. 2 Kaplan-Meier curve for recurrence-free survival according to CD98hc status in all patients. RFS in all patients did not differ significantly between CD98hc-positive and CD98hc-negative groups (Five-year RFS rate, $60.7 \%$ vs $58.7 \%, P=0.690$ )

In CD98hc expression, GSH and cysteine levels and GSH/GSSG ratio were significantly higher in the CD98hc-positive group than in the CD98hc-negative group, although GSSG levels did not differ significantly between CD98hc-positive and -negative groups.

Concentrations of metabolites involved in glycolysis and PPP are illustrated on the metabolic pathway map in Fig. 4. Lactate levels were higher in the CD44v9-positive group than in the CD4v9-negative group. In addition, regarding glycolysis, 3-phosphoglyceric acid levels were significantly higher in CD44v9-positive patients than in the CD44v9-negative patients. Levels of ribulose 5-phosphate in PPP were significantly higher in the CD44v9-positive group than in the CD44v9-negative group, whereas metabolic intermediates in glycolysis and PPP showed no significant differences between CD98hc-positive and -negative groups.

Levels of amino acids such as Leu, Ile, Ser, Cys, Met, Asn, Try, Phe, Lys, Thr, Val, Pro, hydroxyproline, and His, with the exceptions of glutamine and glutamate, were significantly higher in the CD98hcpositive group than in the CD98hc-negative group (Fig. 5), although levels of all amino acids (including glutamine and glutamate) did not differ significantly between CD44v9-positive and -negative groups (data not shown).

\section{DISCUSSION}

Prior works have documented that expression of CD44v9, a marker of cancer stem-like cells, contrib- 
Table 3 Uni- and multivariate analyses for recurrence-free survival of the patients with gastric cancer by surgery

\begin{tabular}{|c|c|c|c|c|c|c|}
\hline \multirow{3}{*}{ characteristic } & \multicolumn{3}{|c|}{ Recurrence-free survival } & \multirow{2}{*}{\multicolumn{3}{|c|}{ Multivariate analysis }} \\
\hline & \multicolumn{3}{|c|}{ Univariate analysis } & & & \\
\hline & hazard ratio & $(95 \% \mathrm{CI})$ & $P$ value & hazard ratio & $(95 \% \mathrm{CI})$ & $P$ value \\
\hline Gender & & & 0.196 & & & \\
\hline Female & Reference & & & & & \\
\hline Male & 1.61 & $0.743-3.256$ & & & & \\
\hline Age (years) & & & 0.632 & & & \\
\hline$<70$ & Reference & & & & & \\
\hline$\geq 70$ & 1.17 & $0.609-2.296$ & & & & \\
\hline CEA (ng/mL) & & & 0.46 & & & \\
\hline$<5.0$ & Reference & & & & & \\
\hline$\geq 5.0$ & 1.35 & $0.577-2.842$ & & & & \\
\hline Tumor size (mm) & & & 0.01 & & & 0.402 \\
\hline$<70$ & Reference & & & Reference & & \\
\hline$\geq 70$ & 2.38 & $1.225-4.846$ & & 1.34 & $0.677-2.784$ & \\
\hline Histologic type & & & 0.009 & & & 0.034 \\
\hline Differentiated & Reference & & & Reference & & \\
\hline Undifferentiated & 2.45 & $1.238-5.201$ & & 2.11 & $1.054-4.547$ & \\
\hline Lymphatic invasion & & & 0.894 & & & \\
\hline Absent & Reference & & & & & \\
\hline Present & 1.05 & $0.482-2.112$ & & & & \\
\hline Venous invasion & & & 0.156 & & & \\
\hline Absent & Reference & & & & & \\
\hline Present & 1.88 & $0.482-2.112$ & & & & \\
\hline Pathological T stage & & & 0.0007 & & & 0.218 \\
\hline $\mathrm{T} 1 / 2$ & Reference & & & Reference & & \\
\hline $\mathrm{T} 3 / 4$ & 10 & $2.166-178.0$ & & 2.94 & $0.598-53.31$ & \\
\hline Pathological N stage & & & $<0.0001$ & & & 0.0005 \\
\hline No & Reference & & & Reference & & \\
\hline N1-3 & 9.06 & $2.758-55.90$ & & 6.92 & $2.074-43.00$ & \\
\hline CD44v9 & & & $<0.0001$ & & & $<0.0001$ \\
\hline Negative & Reference & & & Reference & & \\
\hline Positive & 5.58 & $2.764-12.18$ & & 4.14 & $1.997-9.286$ & \\
\hline CD98hc & & & 0.295 & & & \\
\hline Negative & Reference & & & & & \\
\hline Positive & 0.69 & $0.342-1.353$ & & & & \\
\hline
\end{tabular}

utes to cancer survival under hostile conditions, such as under conditions of high ROS generation, by increasing intracellular levels of GSH $(25,37)$. In this study, we examined the effects of CD44v9 expression using immunohistochemical and metabolomic analyses in a series of patients with advanced gastric cancer. CD44v9 expression was identified as an independent predictor of tumor recurrence in gastric cancer. Analysis of the metabolome found that metabolic intermediates in glycolysis and PPP were significantly higher, levels of GSSG were significantly lower, and GSH/GSSG ratio was significantly higher for CD44v9-positive tumors than for CD44v9negative tumors, suggesting that CD44v9 may enhance PPP flux and maintain GSH levels in cancer cells.
CD44v9 as an independent predictor of tumor recurrence in gastric cancer

Our results revealed CD44v9 expression as an independent predictor of tumor recurrence in gastric cancer. Histological evidence of CD44v9 expression has also recently been reported for several types of cancer, such as gastric cancer, hepatocellular carcinoma, ovarian cancer, colorectal cancer, and urothelial cancer (19-21, 31, 33, 42). Hirata et al. reported that CD44v9 may serve as a novel indicator of stage I gastric cancer after endoscopic submucosal dissection (21). Specifically, they showed that among 65 patients who underwent endoscopic submucosal dissection for stage I gastric cancer, 13 developed multiple recurrences. Furthermore, Go et al. suggested that positive immunoexpression of CD44v9 serves 


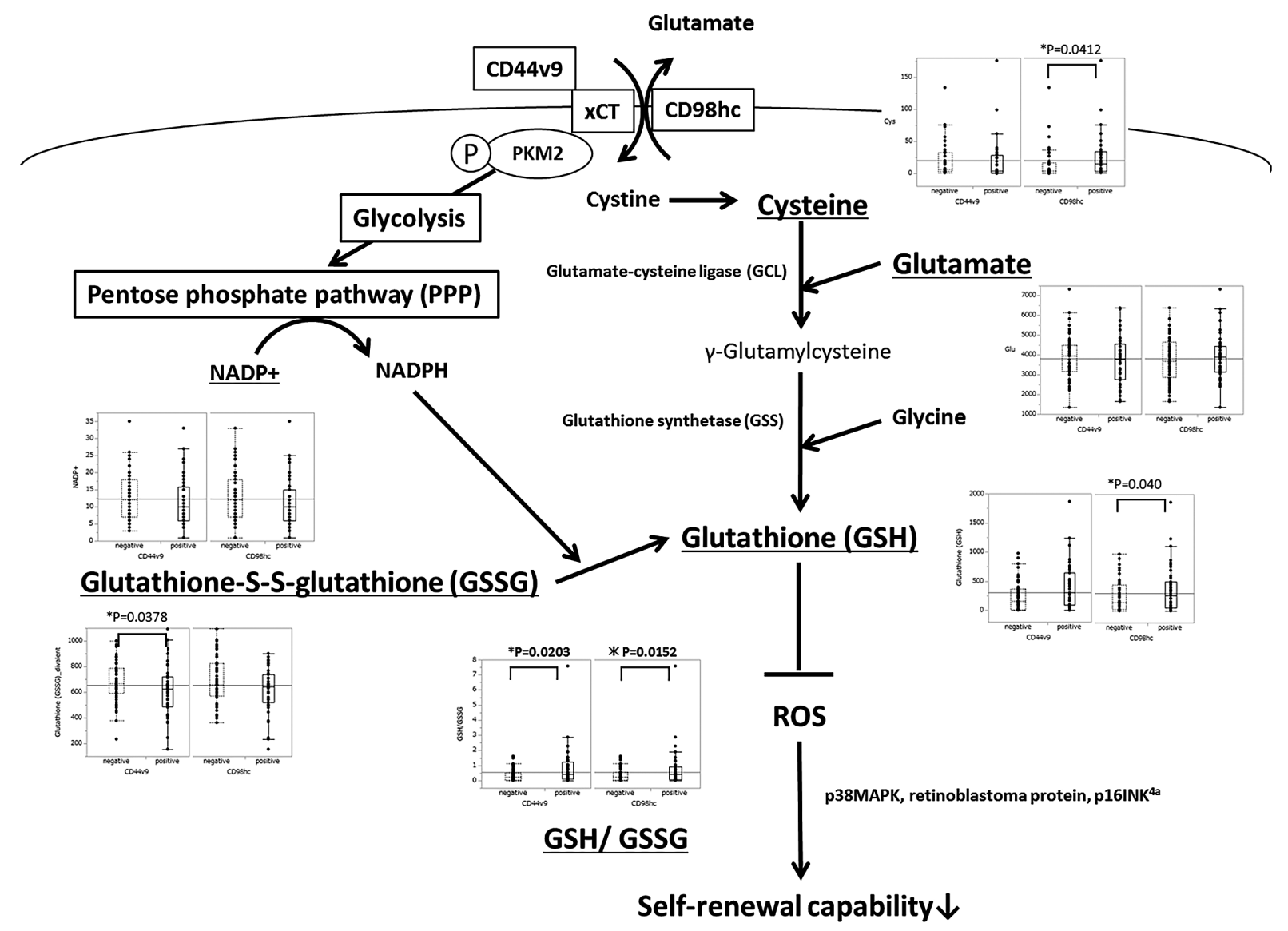

Fig. 3 Glutathione metabolism. Metabolite concentrations in CD44v9 and CD98hc expression groups superimposed on a metabolic pathway map included glutathione metabolism. Columns, median concentration (nmol/g). All $P$ values were evaluated using the Wilcoxon matched pair test. ${ }^{*} P<0.05$ PKM2: pyruvate kinase M2; NADPH: reduced nicotinamide adenine dinucleotide phosphate; NADP+: nicotinamide adenine dinucleotide phosphate; ROS: reactive oxygen species; p38MAPK: mitogen-activated protein kinase p38; p16INK ${ }^{4 a}$ : cyclin dependent kinase inhibitors p16

as a predictor of poor prognosis in stage I, but not in stage II or III (19). They reported 5-year overall survival rates of $81.7 \%$ in the CD44v9-positive group and $95.2 \%$ in the CD44v9-negative group, showing a significant difference between groups. Consequently, the rate of stage I gastric cancer recurrence and poor prognosis was significantly higher in the CD44v9-positive group than in the CD44v9-negative group. In the present study, however, positive immunoexpression of CD44v9 served as an indicator of recurrence in all patients who underwent gastrectomy for gastric cancer. Then, in terms of TNM stage, we showed that the rate of recurrence was significantly higher in the CD44v9-positive group than in the CD44v9-negative group in stage III. That is, we showed that CD44v9 serves as a marker of recurrence for advanced gastric cancer after gastrectomy. In a previous study, CD44v9 was associated with lymph node metastasis, depth of in- vasion, and pathological TNM stage in gastric cancer (51). Those results support the present findings in which multivariate analysis identified undifferentiated histological type, positive lymph node metastasis and positive CD44v9 expression as independent prognostic factors for RFS.

\section{Metabolomic analyses of gastric cancer tissues}

To the best of our knowledge, this represents the first study to focus on energy metabolism in association with CD44v9 expression in surgically resected gastric cancer tissues. In metabolome analyses, levels of GSSG were significantly lower and GSH/ GSSG ratio was significantly higher in the CD44v9positive group than in the $\mathrm{CD} 44 \mathrm{v} 9$-negative group for gastric cancer. On the other hand, GSH levels did not differ significantly between groups. In addition, levels of lactate, 3-phosphoglyceric acid and ribulose 5-phosphate were higher in the CD44v9- 


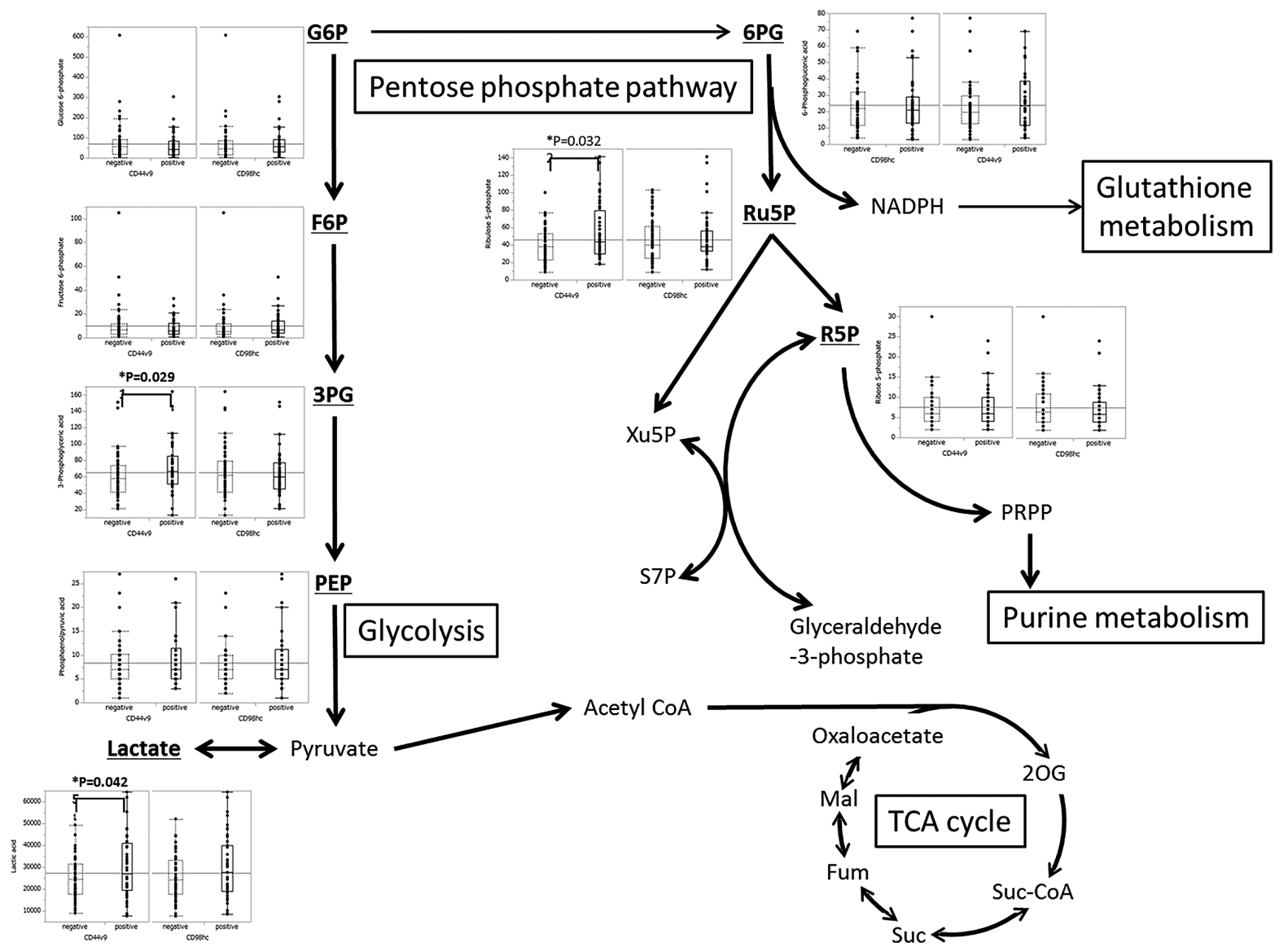

Fig. 4 Quantified levels of metabolites involved in central carbon metabolism. Metabolite concentrations of CD44v9 expression and CD98hc expression groups superimposed on a metabolic pathway map that includes glycolysis and the pentose phosphate pathway. Columns, median concentration $(\mathrm{nmol} / \mathrm{g})$. All P-values were evaluated using the Wilcoxon matched pair test. ${ }^{*} P<0.05$ G6P: glucose-6-phosphate; F6P: fructose 6-phosphate; 3PG: glycerate 3-phosphate; PEP: phosphoenolpyruvic acid; 6PG: 6-phosphogluconate; Ru5P: ribulose 5-phosphate; R5P: ribose 5-phosphate; X5P: D-xylulose 5-phosphate; NADPH: reduced nicotinamide adenine dinucleotide phosphate; S7P: sedoheptulose 7-phosphate; PRPP: 5-phosphoribosyl 1-diphosphate; 2OG: 2-oxoglutaric acid; Suc-CoA: succinyl-CoA; Suc: succinic acid; Fum: fumaric acid; Mal: malic acid

positive group than in the CD44v9-negative group. Blatt et al. reported that lactate offers a predictor of tumor recurrence in patients with head and neck cancer (6). Furthermore, Martínez et al. reported that acidic $\mathrm{pH}$, representing increased lactate, enhances the invasive behavior of human melanoma cells (36). However, no studies have reported on lactate associated with gastric cancer recurrence. High lactate levels clearly indicate enhanced lactate fermentation, which reaffirmed the Warburg effect in the CD44v9-positive group. Recent studies have shown that pyruvate kinase M2 is a key glycolytic enzyme that regulates the Warburg effect and is necessary for tumor growth (10). Tamada et al. reported that CD44 maintains GSH levels in cancer cells because CD44v and pyruvate kinase M2 interactions regulate GSH production (44). Interactions between
CD44v and pyruvate kinase M2 suppress enzymatic activity via tyrosine phosphorylation and promote glycolysis, and increase flux to PPP that produces NADPH, contributing to increased GSH production from GSSG in glycolytic cancer cells. Our results support the notion that CD44v9 enhances PPP flux that produces NADPH, contributing to changes from GSSG to GSH and maintaining GSH levels in cancer cells.

Prognostic role of CD98hc and CD98 amino acid transport in gastric cancer

In the present study, expression of CD98he was not identified as an independent prognostic factor for RFS in gastric cancer patients. A recent study reported that CD98 expression represents a significant predictor of poor outcome in squamous cell carcino- 


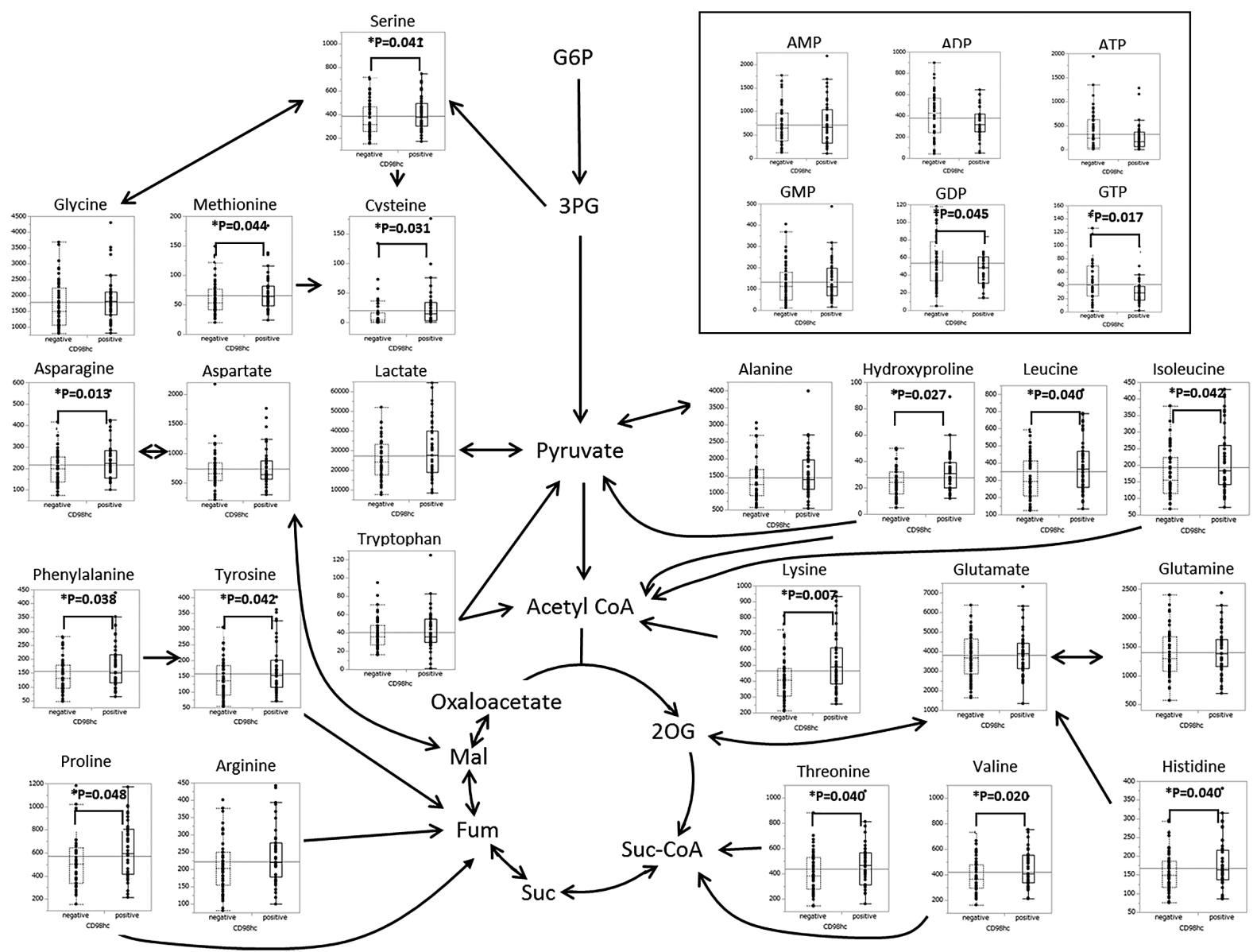

Fig. 5 Metabolome data map of metabolites including amino acids and nucleotides (shown in the box) in CD98hc-negative and CD98hc-positive groups. Columns show median concentration (nmol/g) in CD98hc-negative and CD98hc-positive groups. All $P$ values were evaluated using the Wilcoxon matched pair test. ${ }^{*} P<0.05$ G6P: glucose-6-phosphate; 3PG: glycerate 3-phosphate; 2OG: 2-oxoglutaric acid; Suc-CoA: succinyl-CoA; Suc: succinic acid; Fum: fumaric acid; Mal: malic acid; AMP: adenosine monophosphate; ADP: adenosine diphosphate; ATP: adenosine triphosphate; GMP: guanosine monophosphate; GDP: guanosine diphosphate; GTP: guanosine triphosphate

ma of the larynx, B-cell lymphoma, and lung cancer, but not in pancreatic cancer $(14,23,29,30)$. Little is known about the correlations between CD98 expression and long-term outcomes in patients with gastric cancer.

In metabolomic analyses, levels of many amino acids, GSH and GSH/GSSG ratio were all significantly higher in the CD98hc-positive group than in the CD98hc-negative group. CD98h plays an important role in amino-acid transport by interact with various types of transporter, such as LAT1 and $\mathrm{xCT}$. LAT1 transports large neutral amino acids such as leucine, isoleucine, valine, phenylalanine, tyrosine, tryptophan, methionine, and histidine, while xCT increases intracellular levels of cysteine $(7,15,32)$. In the present study, metabolomic profiles suggested that intracellular amino acid concentrations and
GSH were higher in CD98hc-expressing tissues, suggesting that CD98hc is associated with amino acid transport in gastric cancer tissues. However, CD98hc is a multifunctional molecule and interacts with many transporters, which is why expression of CD98hc may not have been identified as an independent prognostic factor for gastric cancer in the present study.

\section{Limitations}

Some limitations to this study must be considered when interpreting the present findings. First, selection bias was present in this study, with more than $90 \%$ of patients showing advanced cancer. Because specific amounts of tumor tissue were collected from surgically resected samples for metabolite extraction, patients with small tumors were excluded 
from the study. Improvements in the devices used for metabolomic analysis to allow measurements from smaller tumors are required.

Second, this study attempted immunohistochemical staining for $\mathrm{xCT}$ in surgically resected tissue samples according to the instructions from the manufacturer, but no tissue slides examined for $\mathrm{xCT}$ showed any staining. To the best of our knowledge, no reports have described staining of anti-xCT antibodies in patients with gastric cancer. This result remains unexplained. Further investigation is required with regard to $\mathrm{xCT}$ in gastric cancer.

\section{Conclusions}

In conclusion, our study confirmed that the recurrence rate of gastric cancer following surgery is higher in the CD44v9-positive tumors than in the CD44v9-negative tumors. The data presented in our study suggest that expression of CD44v9 may offer a new biomarker of recurrence in gastric cancer. To the best of our knowledge, this is the first study to focus on energy metabolism in association with CD44v9 expression in gastric cancer. Levels of GSSG were significantly lower and the GSH/GSSG ratio was significantly higher in the CD44v9-positive group than in the CD44v9-negative group in gastric cancer. These findings suggest that CD44v9 may enhance PPP flux and maintain GSH levels in cancer cells.

\section{Acknowledgements}

We wish to thank all the staff of the Pathology Department at Shizuoka Cancer Center for their technical assistance in immunohistochemical analyses. This research was supported by a grant for Practical Research for Innovative Cancer Control (\#15ck0106043h0002) from the Japan Agency for Medical Research and Development, AMED.

\section{REFERENCES}

1. International Agency for Research on Cancer WHO (2012) GLOBOCAN 2012. Estimated cancer incidence, mortality and prevalence.

2. Al Hajj M, Wicha M, Benito Hernandez A, Morrison S and Clarke M (2003) Prospective identification of tumorigenic breast cancer cells. Proc Natl Acad Sci USA 100, 3983-3988.

3. Aruffo A, Stamenkovic I, Melnick M, Underhill CB and Seed B (1990) CD44 is the principal cell surface receptor for hyaluronate. Cell 61, 1303-1313.

4. Aso T, Matsuo M, Kiyohara H, Taguchi K, Rikimaru F, et al. (2015) Induction of CD44 variant 9-expressing cancer stem cells might attenuate the efficacy of chemoradioselection and Worsens the prognosis of patients with advanced head and neck cancer. PloS One 10, e0116596-e0116596.
5. Betsunoh H, Fukuda T, Anzai N, Nishihara D, Mizuno T, et al. (2013) Increased expression of system large amino acid transporter (LAT)-1 mRNA is associated with invasive potential and unfavorable prognosis of human clear cell renal cell carcinoma. BMC Cancer 13, 509-509.

6. Blatt S, Voelxen N, Sagheb K, Pabst A, Walenta S, et al. (2016) Lactate as a predictive marker for tumor recurrence in patients with head and neck squamous cell carcinoma (HNSCC) post radiation: a prospective study over 15 years. Clin Oral Investig 20, 2097-2104.

7. Boulter E, Estrach S, Errante A, Pons C, Cailleteau L, et al. (2013) CD98hc (SLC3A2) regulation of skin homeostasis wanes with age. $J$ Exp Med 210, 173-190.

8. Campbell WA, Sah DE, Medina MM, Albina JE, Coleman WB, et al. (2000) TA1/LAT-1/CD98 light chain and system $\mathrm{L}$ activity, but not 4F2/CD98 heavy chain, respond to arginine availability in rat hepatic cells. Loss Of response in tumor cells. J Biol Chem 275, 5347-5354.

9. Cantor J and Ginsberg M (2012) CD98 at the crossroads of adaptive immunity and cancer. $J$ Cell Sci 125, 1373-1382.

10. Christofk H, Vander Heiden M, Harris M, Ramanathan A, Gerszten R, et al. (2008) The M2 splice isoform of pyruvate kinase is important for cancer metabolism and tumour growth. Nature 452, 230-233.

11. Collins A, Berry P, Hyde C, Stower M and Maitland N (2005) Prospective identification of tumorigenic prostate cancer stem cells. Cancer Res 65, 10946-10951.

12. Culty M, Miyake K, Kincade PW, Sikorski E, Butcher EC, et al. (1990) The hyaluronate receptor is a member of the CD44 (H-CAM) family of cell surface glycoproteins. J Cell Biol 111, 2765-2774.

13. Diehn M, Cho R, Lobo N, Kalisky T, Dorie M, et al. (2009) Association of reactive oxygen species levels and radioresistance in cancer stem cells. Nature 458, 780-783.

14. Esteban F, Ruiz Cabello F, Concha A, Perez Ayala M, Delgado M, et al. (1990) Relationship of 4F2 antigen with local growth and metastatic potential of squamous cell carcinoma of the larynx. Cancer 66, 1493-1498.

15. Estrach S, Lee S-A, Boulter E, Pisano S, Errante A, et al. (2014) CD98hc (SLC3A2) loss protects against ras-driven tumorigenesis by modulating integrin-mediated mechanotransduction. Cancer Res 74, 6878-6889.

16. Furnham N, Ruffle S and Southan C (2004) Splice variants: a homology modeling approach. Proteins 54, 596-608.

17. Furuya M, Horiguchi J, Nakajima H, Kanai $Y$ and Oyama $T$ (2012) Correlation of L-type amino acid transporter 1 and CD98 expression with triple negative breast cancer prognosis. Cancer Sci 103, 382-389.

18. Günthert U, Hofmann M, Rudy W, Reber S, Zöller M, et al. (1991) A new variant of glycoprotein CD44 confers metastatic potential to rat carcinoma cells. Cell $\mathbf{6 5}, 13-24$.

19. Go SI, Ko GH, Lee WS, Kim R, Lee JH, et al. (2016) CD44 variant 9 serves as a poor prognostic marker in early gastric cancer, but not in advanced gastric cancer. Cancer Res Treat 48, 142-152.

20. Hagiwara M, Kikuchi E, Kosaka T, Mikami S, Saya H, et al. (2016) Variant isoforms of CD44 expression in upper tract urothelial cancer as a predictive marker for recurrence and mortality. Urol Oncol 34, e19-26.

21. Hirata K, Suzuki H, Imaeda H, Matsuzaki J, Tsugawa H, et al. (2013) CD44 variant 9 expression in primary early gastric cancer as a predictive marker for recurrence. $\mathrm{Br} J$ Cancer 109, 379-386.

22. Hirayama A, Kami K, Sugimoto M, Sugawara M, Toki N, et 
al. (2009) Quantitative metabolome profiling of colon and stomach cancer microenvironment by capillary electrophoresis time-of-flight mass spectrometry. Cancer Res 69, 49184925.

23. Holte H, Davies CD, Kvaløy S, Smeland EB, Foss Abrahamsen A, et al. (1987) The activation-associated antigen 4F2 predicts patient survival in low-grade B-cell lymphomas. Int $J$ Cancer 39, 590-594.

24. Ichinoe M, Mikami T, Yoshida T, Igawa I, Tsuruta T, et al. (2011) High expression of L-type amino-acid transporter 1 (LAT1) in gastric carcinomas: comparison with non-cancerous lesions. Pathol Int 61, 281-289.

25. Ishimoto T, Nagano O, Yae T, Tamada M, Motohara $\mathrm{T}$, et al. (2011) CD44 variant regulates redox status in cancer cells by stabilizing the $\mathrm{xCT}$ subunit of system $\mathrm{xc}(-)$ and thereby promotes tumor growth. Cancer Cell 19, 387-400.

26. Ishimoto T, Oshima H, Oshima M, Kai K, Torii R, et al. (2010) $\mathrm{CD}_{4} 4^{+}$slow-cycling tumor cell expansion is triggered by cooperative actions of Wnt and prostaglandin E2 in gastric tumorigenesis. Cancer Sci 101, 673-678.

27. Jayavelu N and Bar N (2014) Metabolomic studies of human gastric cancer: review. World J Gastroenterol 20, 8092-8101.

28. Kaira K, Oriuchi N, Imai H, Shimizu K, Yanagitani N, et al. (2009) Prognostic significance of L-type amino acid transporter 1 (LAT1) and 4F2 heavy chain (CD98) expression in early stage squamous cell carcinoma of the lung. Cancer Sci 100, 248-254.

29. Kaira K, Oriuchi N, Imai H, Shimizu K, Yanagitani N, et al. (2009) CD98 expression is associated with poor prognosis in resected non-small-cell lung cancer with lymph node metastases. Ann Surg Oncol 16, 3473-3481.

30. Kaira K, Sunose Y, Arakawa K, Ogawa T, Sunaga N, et al. (2012) Prognostic significance of L-type amino-acid transporter 1 expression in surgically resected pancreatic cancer. Br J Cancer 107, 632-638.

31. Kakehashi A, Ishii N, Sugihara E, Gi M, Saya H, et al. (2016) CD44 variant 9 is a potential biomarker of tumor initiating cells predicting survival outcome in hepatitis $\mathrm{C}$ virus-positive patients with resected hepatocellular carcinoma. Cancer Sci 107, 609-618.

32. Kanai Y, Segawa H, Miyamoto K, Uchino H, Takeda E, et al. (1998) Expression cloning and characterization of a transporter for large neutral amino acids activated by the heavy chain of 4F2 antigen (CD98). J Biol Chem 273, 2362923632.

33. Katoh S, Goi T, Naruse T, Ueda Y, Kurebayashi $\mathrm{H}$, et al. (2015) Cancer stem cell marker in circulating tumor cells: expression of CD44 variant exon 9 is strongly correlated to treatment refractoriness, recurrence and prognosis of human colorectal cancer. Anticancer Res 35, 239-244.

34. Liang Q, Wang C and Li B (2015) Metabolomic analysis using liquid chromatography/mass spectrometry for gastric cancer. Appl Biochem Biotechnol 176, 2170-2184.

35. Lin LL, Huang HC and Juan HF (2012) Discovery of biomarkers for gastric cancer: a proteomics approach. J Proteomics 75, 3081-3097.

36. Martínez Zaguilán R, Seftor EA, Seftor RE, Chu YW, Gillies $\mathrm{RJ}$, et al. (1996) Acidic pH enhances the invasive behavior of human melanoma cells. Clin Exp Metastasis 14, 176-186.
37. Nagano O, Okazaki S and Saya H (2013) Redox regulation in stem-like cancer cells by CD44 variant isoforms. Oncogene 32, 5191-5198.

38. Nagano O and Saya H (2004) Mechanism and biological significance of CD44 cleavage. Cancer Sci 95, 930-935.

39. Ohashi Y, Hirayama A, Ishikawa T, Nakamura S, Shimizu K, et al. (2008) Depiction of metabolome changes in histidine-starved Escherichia coli by CE-TOFMS. Mol Biosyst 4, 135-147.

40. Ooga T, Sato H, Nagashima A, Sasaki K, Tomita M, et al. (2011) Metabolomic anatomy of an animal model revealing homeostatic imbalances in dyslipidaemia. Mol Biosyst 7, $1217-1223$.

41. Reya T, Morrison SJ, Clarke MF and Weissman IL (2001) Stem cells, cancer, and cancer stem cells. Nature 414, 105111.

42. Sosulski A, Horn H, Zhang L, Coletti C, Vathipadiekal V, et al. (2016) CD44 splice variant v8-10 as a marker of serous ovarian cancer prognosis. PloS One 11, e0156595-e0156595.

43. Sugimoto M, Wong DT, Hirayama A, Soga T and Tomita M (2010) Capillary electrophoresis mass spectrometry-based saliva metabolomics identified oral, breast and pancreatic cancer-specific profiles. Metabolomics 6, 78-95.

44. Tamada M, Suematsu M and Saya H (2012) Pyruvate kinase M2: multiple faces for conferring benefits on cancer cells. Clin Cancer Res 18, 5554-5561.

45. Thomas L, Byers HR, Vink J and Stamenkovic I (1992) $\mathrm{CD} 44 \mathrm{H}$ regulates tumor cell migration on hyaluronate-coated substrate. J Cell Biol 118, 971-977.

46. Wada T, Ishimoto T, Seishima R, Tsuchihashi K, Yoshikawa $\mathrm{M}$, et al. (2013) Functional role of CD44v-xCT system in the development of spasmolytic polypeptide-expressing metaplasia. Cancer Sci 104, 1323-1329.

47. Warzecha C, Sato T, Nabet B, Hogenesch JB and Carstens RP (2009) ESRP1 and ESRP2 are epithelial cell-type-specific regulators of FGFR2 splicing. Mol Cell 33, 591-601.

48. Yamaguchi A, Urano T, Goi T, Saito M, Takeuchi K, et al. (1996) Expression of a CD44 variant containing exons 8 to 10 is a useful independent factor for the prediction of prognosis in colorectal cancer patients. J Clin Oncol 14, 11221127.

49. Yanagisawa N, Ichinoe M, Mikami T, Nakada N, Hana K, et al. (2012) High expression of L-type amino acid transporter 1 (LAT1) predicts poor prognosis in pancreatic ductal adenocarcinomas. J Clin Pathol 65, 1019-1023.

50. Yanagisawa N, Satoh T, Hana K, Ichinoe M, Nakada N, et al. (2015) L-amino acid transporter 1 may be a prognostic marker for local progression of prostatic cancer under expectant management. Cancer Biomark 15, 365-374.

51. Yasui W, Kudo Y, Naka K, Fujimoto J, Ue T, et al. (1998) Expression of CD44 containing variant exon 9 (CD44v9) in gastric adenomas and adenocarcinomas: relation to the proliferation and progression. Int J Oncol 12, 1253-1258.

52. Yoshikawa M, Tsuchihashi K, Ishimoto T, Yae T, Motohara T, et al. (2013) xCT inhibition depletes CD44v-expressing tumor cells that are resistant to EGFR-targeted therapy in head and neck squamous cell carcinoma. Cancer Res 73, 18551866. 
Immunohistochemical and metabolomics analysis of gastric cancer

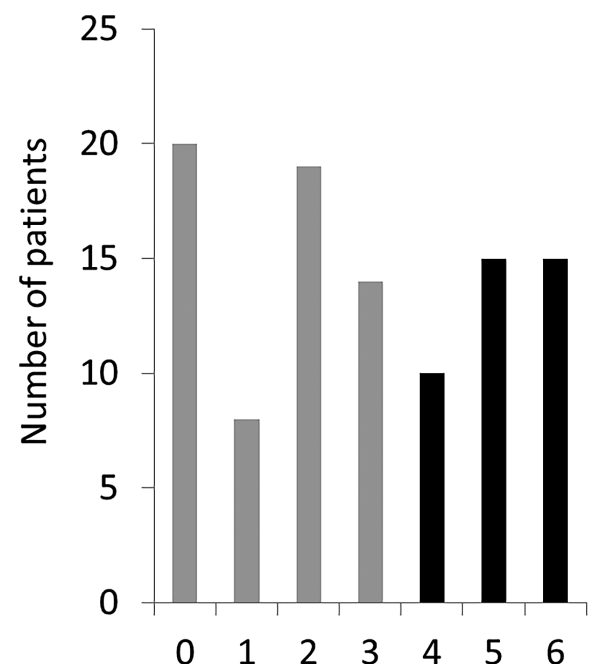

CD44v9 IHC score

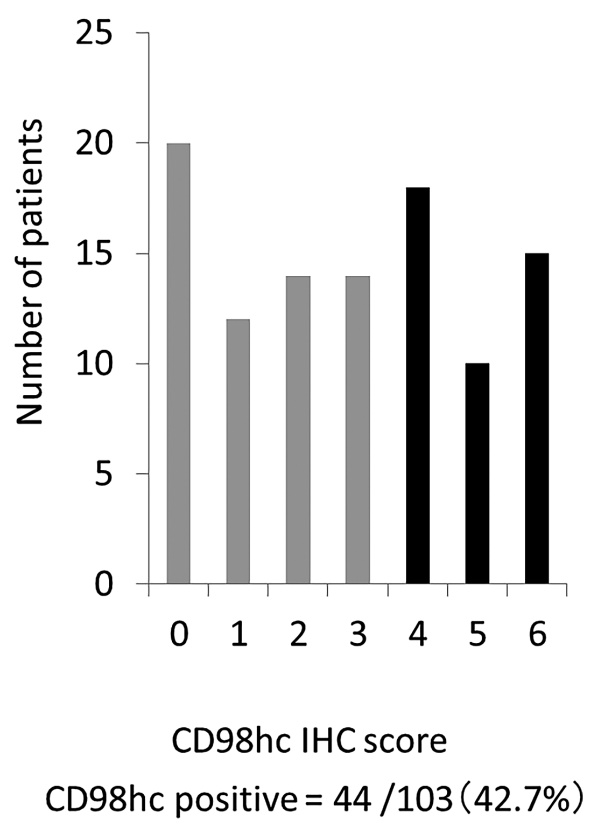

Supplementary Fig. 1 Histogram of CD44v9 and CD98hc immunoreactive scores for all 103 patients. The $\mathrm{x}$ axis shows the immunoreactive scores and the y axis shows the number of patients. CD44v9: CD44 variant 9 

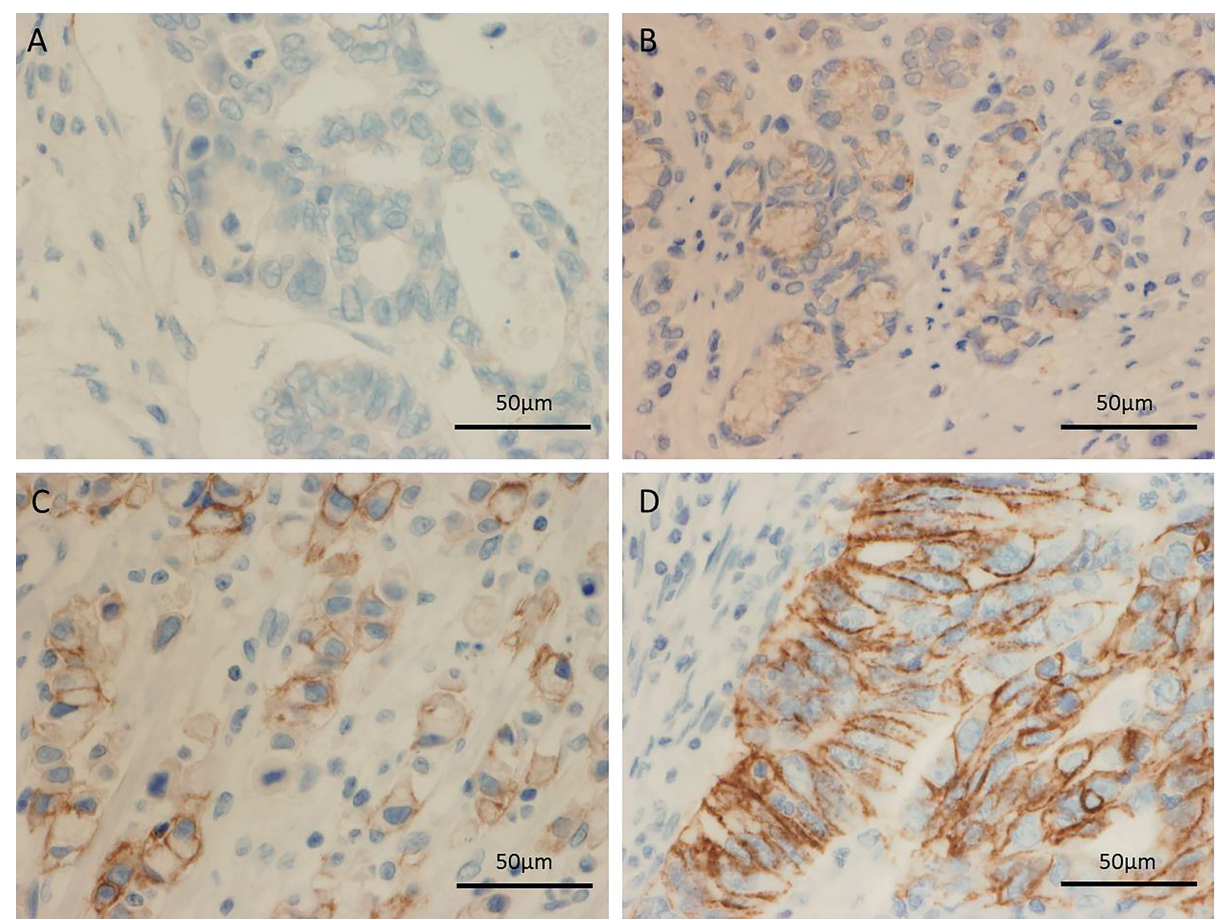

Supplementary Fig. 2A Representative figures of immunohistochemical staining for CD44v9 expression on the basis of positive criteria. Membranous reactions were scored in accordance with the intensity of cellular staining and the proportion of stained tumor cells as follows: (A) 0 , no staining; (B) 1+, weak staining; (C) 2+, moderate staining; (D) $3+$, strong staining. The bar indicates $50 \mu \mathrm{m}$.
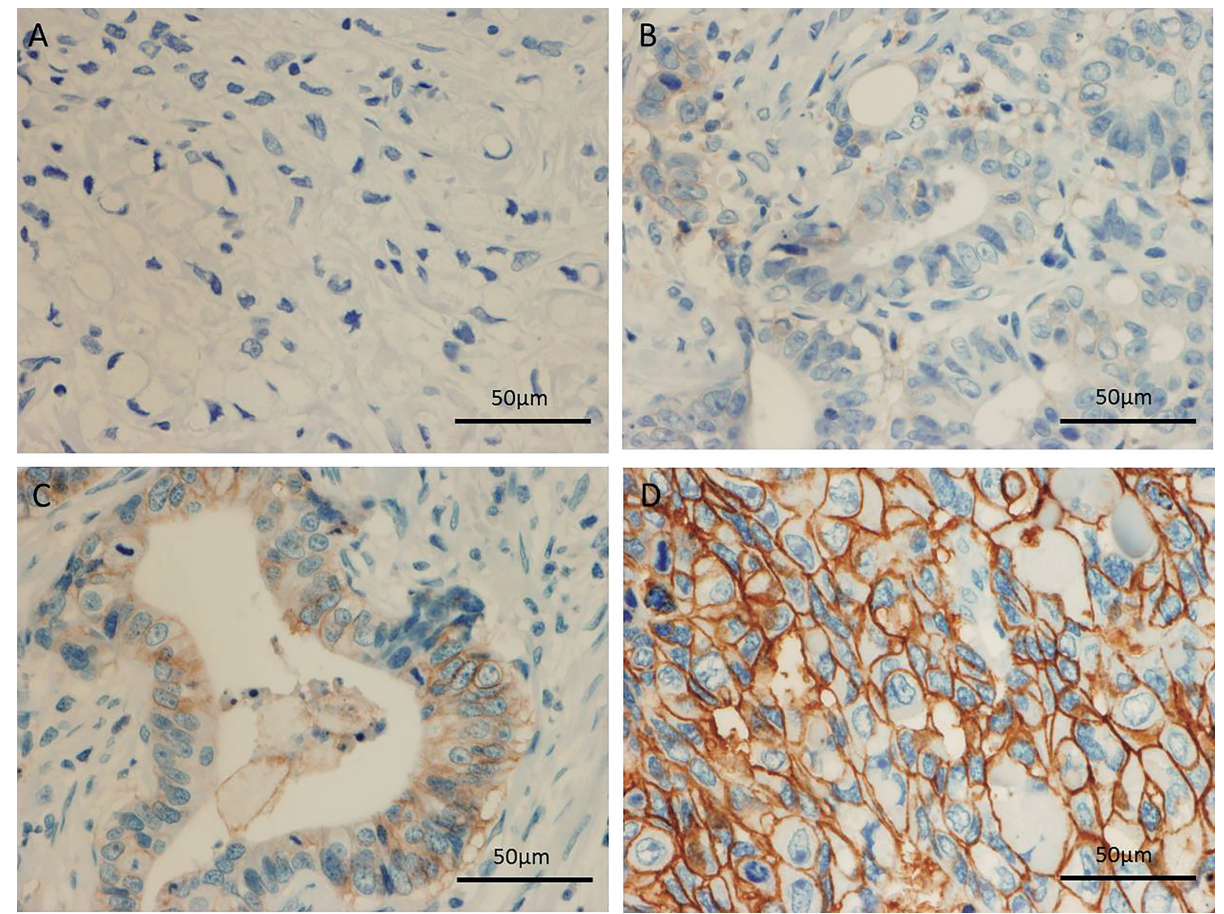

Supplementary Fig. 2B Representative figures of immunohistochemical staining for CD98hc expression on the basis of positive criteria. Membranous reactions were scored in accordance to the intensity of cellular staining and the proportion of stained tumor cells as follows: (A) 0 , no staining, (B) $1+$, weak staining, (C) $2+$, moderate staining, (D) $3+$, strong staining. The bar indicates $50 \mu \mathrm{m}$. 
Immunohistochemical and metabolomics analysis of gastric cancer
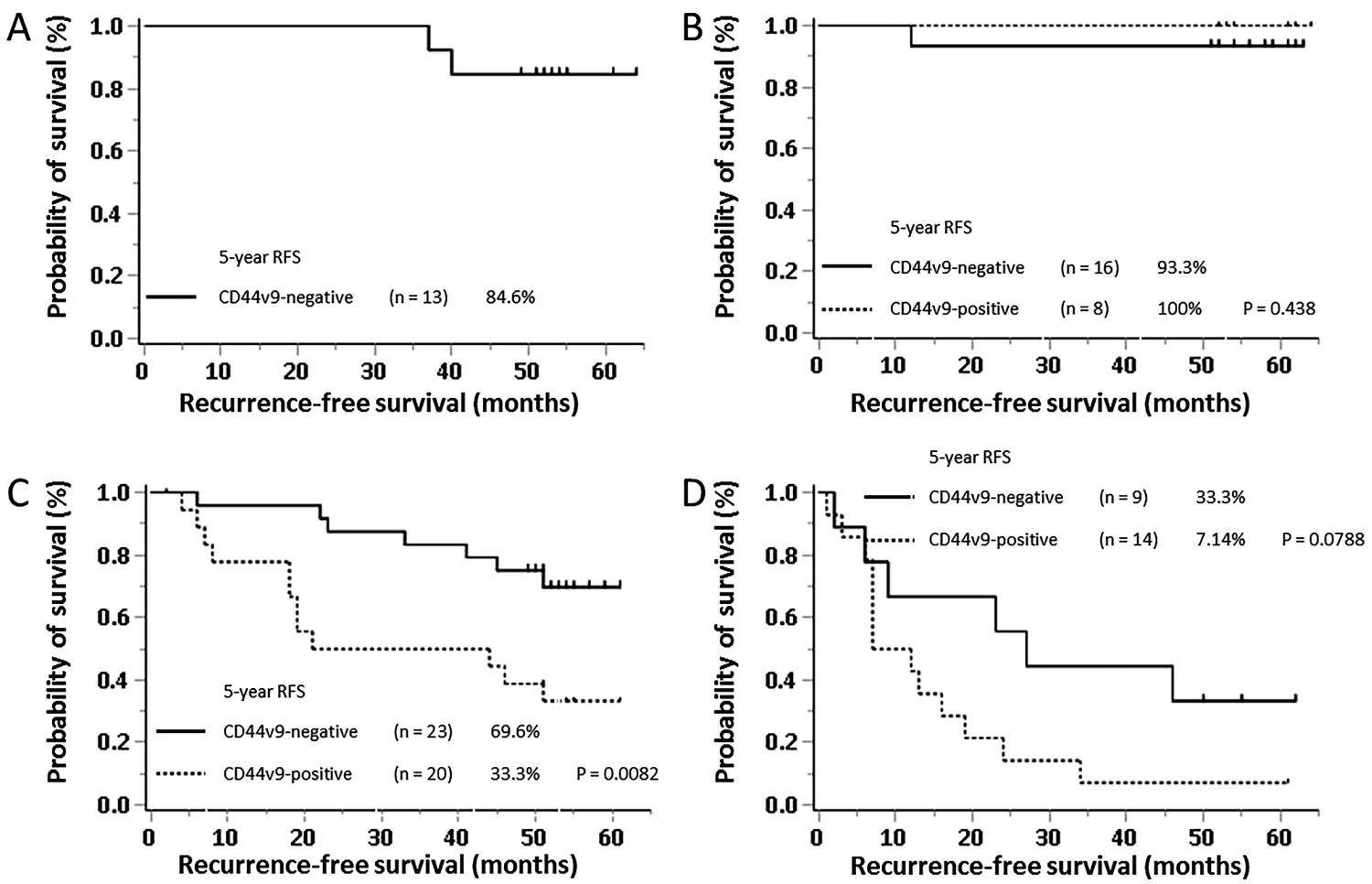

Supplementary Fig. 3 Kaplan-Meier curves for RFS according to CD44v9 status in patients with TNM stage: stage I (A), stage II (B), stage III (C), and stage IV (D). 